\title{
An Evaluation of the Knowledge and Practices of Metro Vancouver Residents Regarding Mould
}

\author{
Chloe LeTourneau-Paci' ${ }^{1}$ Helen Heacock ${ }^{2}$ \\ 1 Lead Author, B.Tech Student, School of Health Sciences, British Columbia Institute of Technology, 3700 Willingdon Ave, Burnaby, BC V5G 3H2 \\ 2 Supervisor, School of Health Sciences, British Columbia Institute of Technology, 3700 Willingdon Ave, Burnaby, BC V5G 3H2
}

\section{ABSTRACT}

Background: The average Canadian spends approximately $90 \%$ of their day indoors, a proportion of which may be in public spaces, thereby making Indoor Air Quality (IAQ) a pertinent topic for the fields of Public and Environmental Health. Mould complaints are one of the top IAQ complaints received by Environmental Health Officers (EHOs) in BC. Mould is ubiquitous in both the outdoor and indoor environment. However, once indoors, mould will grow unhindered on most surfaces as long as moisture is present. Accumulating evidence has established relationships between indoor environments and health. Thanks to the Internet, the amount of readily available information regarding mould today is vast but may not necessarily be valid nor reliable. It is important, therefore, to consider what the public does or does not know and where they are getting their information. This study evaluated the public perception of Metro Vancouver residents in regards to mould as an IAQ issue in order to provide Public and Environmental Health practitioners, including EHOs, with a deeper understanding of how to effectively address queries from the public regarding this topic.

Methods: Data for this study was collected through a self-administered online questionnaire and disseminated using social media and the snowball effect. Questions were designed to collect demographic information and evaluate the knowledge and attitudes as well as the behaviour and practices of participants. Descriptive and inferential statistics, specifically the independent samples t-test and the analysis of variance (ANOVA), were used to analyze the results.

Results: With an average 14.59 out of 20 points, respondent knowledge scores were, in general, fair. There was no statistically significant difference between respondent knowledge score and their gender, age, level of education, income or housing status.

Conclusions: Although respondent knowledge scores were fair, a few gaps in knowledge were identified. Further, most of the sample population did not know specifically where to access reliable information on mould. These insights may be useful for Public and Environmental Health professionals when addressing queries from the public regarding this topic.

Keywords: mould, mold, Indoor Air Quality, indoor environment, environmental health, public health, knowledge, Metro Vancouver, British Columbia

\section{INTRODUCTION}

The average person spends approximately $90 \%$ of their day indoors, a proportion of which may be in public spaces, thereby making Indoor Air Quality (IAQ) a pertinent topic for the fields of Public and
Environmental Health. IAQ is a subject area of Public and Environmental Health which all students in the ENVH field are instructed in. $(1,2)$ As part of this education, students are taught that IAQ investigations are often complex and multifactorial but that 
ultimately education is an Environmental Health Officer (EHO)'s greatest tool in addressing complaints regarding mould. Because there is a wealth of information on this topic, both reliable and unreliable, public perception is an important component of how Public and Environmental Health professionals address queries from the public. A recent study conducted by another BCIT student showed that mould complaints are one of the top IAQ complaints received by EHOs in British Columbia (BC). (3) The objective of the research project was to evaluate the public perception of Metro Vancouver residents regarding mould, specifically existing knowledge levels and practices, as well as where the public is likely to find information on the topic. This may help Public and Environmental Health professionals gain a deeper understanding of how to effectively address complaints or queries from the public regarding this topic.

\section{LITERATURE REVIEW}

\section{Mould in the Environment}

Mould is ubiquitous in both the outdoor and indoor environment, $(1,4-8)$ with indoor levels generally being lower than outdoor levels. (9) Mould (also known as mold) can be referred to as fungus, plural fungi, or mildew. These eukaryotic microorganisms are incredibly resilient and adaptable and consist of a large number of different species which propagate by way of spore and spread readily with the help of air currents. (1,9-11) Another method of spread is mechanical transfer, such as the displacement of a mould-covered material or accidental brushing and then subsequent depositing to a new location. (8) Mould can even be found in dust and once a colony is disturbed, spores can become airborne and spread readily throughout the environment. $(8,9,12)$ That being said, the presence of mould alone does not correspond to exposure but rather to the potential for exposure. (4) Further, in order to germinate, and therefore continue to propagate, mould requires appropriate conditions. These conditions include a non-specific food source, suitable temperature and, most importantly, the presence of water. (11)

\section{Contributing Factors}

Once indoors, mould will grow unhindered on most surfaces as long as moisture is present. $(6,8)$ These microorganisms can utilize a large diversity of different organic materials as their nutrient source including many building materials such as drywall, insulation and wood. (9) However, without moisture, mould cannot propagate and may become dormant until favorable conditions are restored. (8) Examples of where mould is regularly capable of growing includes bathrooms, basements, and water-damaged walls or ceilings. There are many different circumstances which may result in excessive moisture levels indoors including but not limited to: surrounding climate, indoor temperature, overcrowding or waterdamaged building materials caused by leaks, condensation or poor ventilation. $(4,6,9,14,15)$

\section{Indoor Environments}

Although EHOs in most jurisdictions in $\mathrm{BC}$ do not explicitly deal with housing issues, they 
may get involved in situations where a tenant who is renting from a landlord requests assistance. Accumulating evidence has established relationships between indoor environments and health, and further indicates that improved indoor environment quality, including IAQ, can yield significant health benefits. (14) Because of this, the quality of building materials and maintenance of indoor environments should not be ignored. Moisture is continuously being generated within indoor environments. (16) For this reason, a building should be constructed in such a way that it allows for the exchange of air between the indoor and outdoor environments. For these reasons, the quality of indoor environments, and therefore indoor air, relies heavily upon good design, good construction and well-maintained building envelopes. (9)

\section{Health Effects}

As mentioned previously, the presence of mould does not necessarily equate exposure. (4) However, if exposure does occur, mould can generate a wide range of health responses depending on multiple factors. Exposure can include dermal contact, inhalation or ingestion. (11) The main factors affecting the severity of the response include the health status of the individual and their susceptibility to disease, the species of mould, as well as the nature and duration of the exposure itself. $(1,11)$ Although there has been much debate regarding the hazards posed by mould exposure in general, a study conducted in 2016 confirmed that "sufficient evidence" existed to establish an association between mould and damp conditions and asthma symptoms in sensitized children. (18) These findings concur with those released by the World Health Organization (WHO) in their 2011 Indoor Air Quality Guidelines. The WHO analyzed several studies which provided strong evidence to suggest that mould or dampness worsened asthma in children. They further determined that there was not enough evidence to establish an association between mould or dampness and any specific health effects. (9)

Most people do not experience significant health effects when exposed to mould. (8) Those individuals who are most likely to experience significant adverse effects from exposure to mould include young children, the elderly, and immunocompromised or chronically ill individuals, particularly those suffering from cardiovascular or respiratory disease. $(1,6)$

Mild reactions have been reported to generally include upper and/or lower respiratory symptoms such as wheezing and coughing, as well as onset and worsening of asthma. $(5,8,13)$ Headache, nausea, flu-like symptoms, and eye and nose irritation, are among some of the other mild health effects. $(6,13,14)$

Although there are no provincial guidelines for British Columbia, Health Canada considers mould growth indoors to be a potential health hazard and released The Residential Indoor Air Quality Guidelines on Moulds in 2007. (19) This document is still in place today. The recommendations within this guideline apply regardless of the species 
of mould and do not include exposure limits. Reducing or eliminating sources of both mould and dampness indoors not only directly addresses the health of the affected occupants, but also has the potential to improve public health in general and consequently, lead to health care cost savings. $(5,7,19)$

\section{Prevention and Remediation}

In order to prevent the growth of mould, without considering building material specifications, it is imperative to control indoor humidity and condensation levels. $(9,16,19-20)$

In the event that prevention is no longer an option, remediation is the next most appropriate course of action. An important component of remediation is timely execution as this can greatly improve outcomes. $(5,22)$ In order to determine whether mould growth is an issue, a careful inspection of the area is necessary. (9) First the cause, or causes, must be identified. Prior to conducting this assessment, the literature agrees that it is necessary to use personal protective equipment including gloves, a N95-rated respirator and eyewear. $(1,8,16)$ The cleaning of affected material should be carried out by following these recommended steps:

1. Clean and remove mould from surfaces with unscented detergent and water,

2. Rinse with clean water and a clean rag,

3. Dry completely using mechanical ventilation. $(8,16,22)$
In fact, Krause et al. confirmed in a controlled study that simple cleaning (as described above) of mouldy gypsum wallboard will effectively remove mould. (12) In the event that the mouldcontaminated material is damaged and cleaning is not possible, removal and replacement of the affected material, while using the protective equipment previously mentioned, is the best solution. $(8,16)$ Additionally, follow-up measures should be determined and upheld. These measures should include incorporating the preventative measures previously outlined as they are important in order to prevent recurrence.

\section{Resources Available to the Public}

Thanks to the Internet, the amount of readily available information regarding mould today is vast but may not necessarily be reliable. It is important, therefore, to consider where the public is getting their information. All five (5) provincial health authorities in BC are responsible for governing, planning and delivering "health-care services within their geographic areas". (23-27) This includes providing the public with information or directing them to educational resources. (14) Public and Environmental Health professionals, including EHOs, play an important role in educating the public and must therefore be knowledgeable in a wide range of topic areas, including IAQ and mould. $(9,17)$

Because current data are unable to support health-based standards or quantitative recommendations for indoor mould exposure, the resources available are limited 
and only offer guidance. $(5,7,14)$ The following are considered reliable sources of information for Public and Environmental Health professionals to forward to the public:

- National Collaborating Center for Environmental Health's "Microbial Investigation Toolkit" (11) and "Mould Remediation

Recommendations" (20)

- Canada Mortgage and Housing Corporation's "Moisture and Air: Householder's Guide" (16)

- Health Canada's "Residential Indoor Air Quality Guidelines: Moulds" (19)

- Government of Canada's “Mould and Your Health" (10)

- HealthLinkBC's “Indoor Air Quality: Mould and Other Biological Contaminants" (28)

- WorkSafeBC's Guidelines "G.4.79 Moulds and indoor air quality" (8) MATERIALS AND METHODS

\section{Description}

Data for this study was collected through a self-administered online questionnaire developed using the survey program Google Forms and disseminated on January 15, 2018 using social media and the snowball effect. (29) Participation in the study required a computer with Internet access. Google Sheets and NCSS 11 were used to conduct the descriptive and inferential statistics used to analyze the collected data. (30-31)

\section{Inclusion and Exclusion Criteria}

Participants were required to be current residents of the Metro Vancouver area including Abbotsford, Anmore, Belcarra, Bowen Island, Burnaby, Coquitlam, Delta, Electoral Area 'A', City of Langley, Langley Township, Lions Bay, Maple Ridge, New Westminster, City of North Vancouver, North Vancouver District, Pitt Meadows, Port Coquitlam, Port Moody, Richmond, Surrey, Vancouver, West Vancouver, White Rock and First Nations Reserves. (32) Those who did not give consent or did not fit the inclusion criteria were excluded from the study.

\section{RESULTS}

\section{Respondent Demographics}

Among the 119 respondents, 52.9\% $(n=63)$ were female, while $47.1 \%(n=56)$ were male. As seen in figure 1, respondent ages were well distributed at $28.6 \%(n=34)$ being 24 years of age and under, $28.6 \%(n=34)$ being $25-30$ years of age, $22.7 \%(n=27)$ being $31-36$ years of age and $20.2 \%$ being 37 years of age and older.

Figure 1. Respondent age

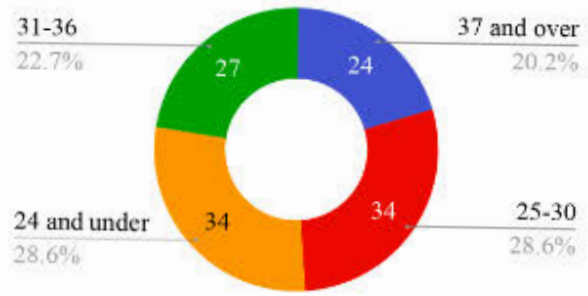

Respondents were spread across the other Metro Vancouver municipalities as follows: Abbotsford at $6.7 \%(n=8)$, Burnaby at $16.0 \%$ $(n=19)$, Coquitlam at $4.2 \%(n=5)$, Delta at $2.5 \%(n=3)$, City of Langley and Township of Langley at $8.4 \%(n=10)$, Maple Ridge at $1.7 \%$ $(n=2)$, New Westminster at 5.0\% $(n=6)$, North Vancouver at $4.2 \%(n=5)$, Port Moody at $0.8 \%(n=1)$, Richmond at $3.4 \%(n=4)$, 
Surrey $16.0 \%(n=19)$, Vancouver at $29.4 \%$ $(n=35)$ and White Rock at $1.7 \%(n=2)$.

Among the respondents, $38.7 \%(n=46)$ had completed high school, had an educational equivalent or less, or had done some form of education higher than high school, $45.4 \%$ ( $n=54)$ had completed some form of postsecondary program (including undergraduate, vocational and technical programs), and $16.0 \%(n=19)$ had completed a graduate or professional degree program.

At a total of $58.0 \%(n=69)$ many respondents were renting their current dwelling while $36.1 \%(n=43)$ owned their current dwelling and $5.9 \%(n=7)$ were either living with their parents or in a co-operative housing situation ('other'), as seen in figure 2 .

Figure 2. Respondent housing status

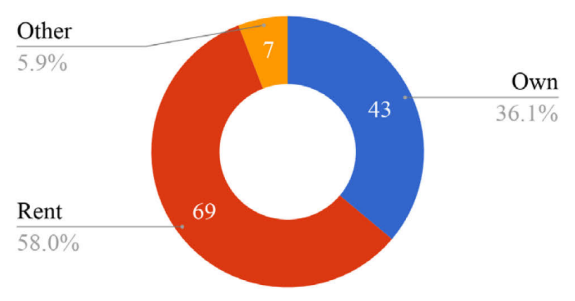

The average annual personal income of respondent's was quite varied: $27.7 \%$ $(n=33)$ of respondent's reported an average annual personal income of less than $\$ 20,000,26.9 \%(n=32)$ reported between $\$ 20,000$ and $\$ 49,000,24.4 \%(n=29)$ reported between $\$ 50,000$ and $\$ 79,000$, $10.9 \%(n=13)$ reported more than $\$ 80,000$, while $10.1 \%(n=12)$ prefered not to answer.

\section{Respondent Knowledge}

As seen in figure 3 , at $93.3 \%(n=111)$, most respondents believed that the quality of the indoor environment did have an impact on health. A total of $5.9 \%(n=7)$ believed that maybe this was the case and $0.8 \%(n=1)$ did not.

Figure 3. Responses to "In your opinion, does the quality of the indoor environment have an impact on health?"

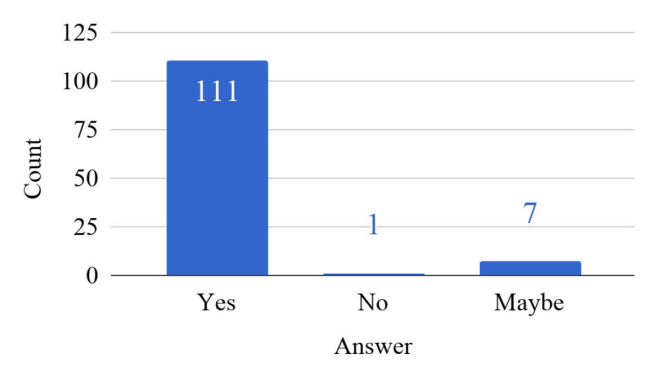

At a total of $86.6 \%(n=103)$, most respondents believed that mould was an indoor air pollutant, while $4.2 \%(n=5)$ believed that this was not the case, $5.0 \%$ $(n=6)$ believed that maybe this was the case and $4.2 \%(n=5)$ did not know.

As seen in figure $4,82.4 \%(n=98)$ of respondents correctly answered (answered "some") the question of whether all or some species of mould can potentially cause harm to humans, $16.0 \%(n=19)$ incorrectly answered (answered "all"), and $1.7 \%(n=2)$ did not know.

Figure 4. Response to "Select the correct answer based on your current knowledge of mould: species of mould can potentially cause harm to humans"

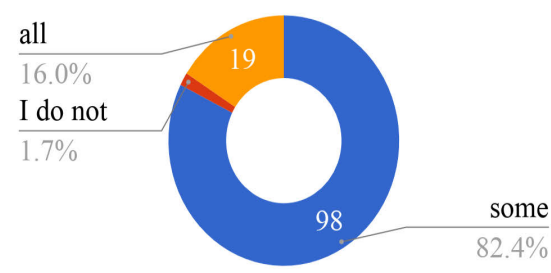

When asked what factors could result in mould growth in indoor environments almost all respondents answered with "limited and/or poor ventilation" $(n=111)$ 
and "high humidity and/or moisture" $(n=116)$. Many respondents also answered with "high temperature" ( $n=77)$, while less answered with "low temperature" ( $n=17)$, "good ventilation" $(n=3)$, "low humidity and/or moisture" $(n=5)$. A total of 3 respondents answered "I do not know". The overall mean knowledge score achieved was 14.59 points out of the possible 20 . Out of the 119 knowledge scores, the lowest knowledge score achieved was 3 points $(n=1)$ while the highest score achieved was 20 points $(n=4)$. More information on the summary statistics for the knowledge scores achieved can be found in table 1.

Table 1. Summary Statistics of Knowledge Scores

\begin{tabular}{cccccccc}
\hline Mean & Median & Mode & $\begin{array}{c}\text { Standard } \\
\text { Deviation }\end{array}$ & Range & Min. & Max. & Count \\
\hline 14.59 & 15 & 18 & 3.50 & 17 & 3 & 20 & 119 \\
\hline
\end{tabular}

The total knowledge score of respondents with counts can be seen in figure 5 .

Figure 5. Respondent Knowledge Scores

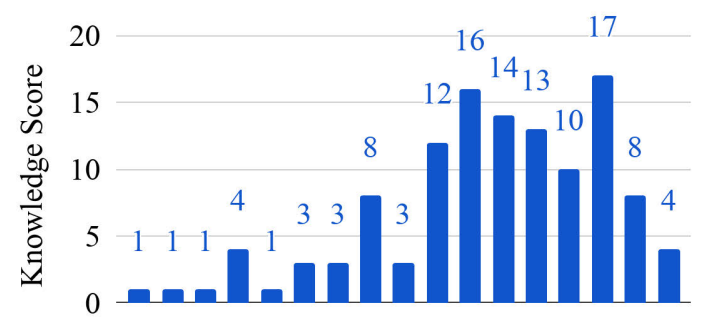

Number of Respondents

When asked what health hazards were associated with the indoor environment most respondents answered "pollution caused by occupants (including smoke, skin, animal fur, dust mites, impurities created during cooking, etc.)" ( $n=108)$ and "biological contaminants (including bacteria, mould, etc.)" ( $n=109)$. More than half of respondents also answered "pollution infiltration from the outdoor environment (including vehicle exhaust, etc.)" ( $n=74)$, and "Emissions of building materials (including flooring, wallpaper, etc.)" ( $n=71)$. While one respondent answered "none of these" and one answered "I do not know".

\section{Respondent Practices}

When asked what actions they would take to reduce indoor air pollution in their dwelling, 108 respondents answered that they would increase ventilation, 94 answered that they would decrease humidity, 76 answered that they would replace their furnace air filter and 83 answered that they would use an air purifier. Other answers included using a fan $(n=36)$, decreasing ventilation $(n=3)$, increasing humidity levels ( $n=5)$, not doing anything $(n=1)$ and "other" $(n=4)$. A total of 6 respondents answered "I do not know". Respondents could select multiple answers. When asked what actions they would take to reduce sources of moisture in their dwelling, 101 respondents answered that they would use a dehumidifier, 52 answered that they would use a fan, 65 answered that they would close their windows while it was raining, 67 answered that they would keep their windows open while it was not raining and 85 answered that they would take shorter showers. Other answers included using a humidifier $(n=1)$, opening windows while it is raining $(n=5)$, keeping their windows closed while it was not raining $(n=3)$, keeping indoor house plants $(n=35)$, not keeping indoor house 
plants $(n=22)$ and other $(n=3)$. A total of 9 respondents answered "I do not know". When asked what they would do if they found a small amount of mould around their bathroom windowsill, most respondents answered that they would clean it themselves ( $n=97)$, some answered that they would use the internet to search for more information ( $n=55)$, some answered that they would search for possible sources $(n=39)$. Other answers included that they would contact their landlord ( $n=24)$, that they would contact the Residential Tenancy Board (RTB) $(n=1)$, that they would contact their regional Health Authority $(H A)(n=2)$, that they would ignore it $(n=11)$, that they would seek advice from a Medical Doctor (MD) $(n=4)$, that they would purchase an at home mould test kit $(n=5)$. A single respondent answered "I do not know".

As a follow up to the previous question posed, participants were asked what measures they would take to protect themselves if they were to clean a small amount of mould themselves, as seen in figure 6. Many respondents answered that they would use rubber gloves $(n=75)$, while fewer answered with "use a face mask" ( $n=48)$, "use protective glasses" $(n=15)$. A total of 38 respondents said they would not use any protective measures while four answered "I do not know".

Figure 6. Respondent answers to: "If you were to clean a small amount of mould yourself, what measures would you take to protect yourself?"

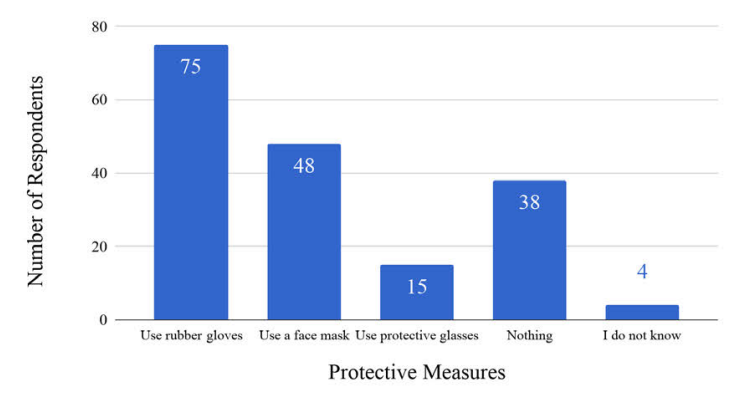

When asked which resources they would use to learn more about mould and mould remediation recommendations, many respondents favoured an internet search over the other options. A total of 112 respondents answered that they would use an internet search, 35 respondents answered that they would ask a friend or family member, 37 respondents answered that they would either call their regional Health Authority (HA) or visit their website (WB), 26 respondents answered that they would visit the HealthLinkBC website, 18 respondents answered that they would visit a Government of Canada website, 8 respondents answered that they would visit the WorkSafeBC website, 7 respondents answered that they would visit the National Collaborating Centre for Environmental Health (NCEEH) website and 3 respondents answered that they would visit the Canadian Mortgage and Housing Corporation (CMHC) website.

\section{Inferential Statistics}

NCSS 11 was used to conduct several inferential statistics including the independent samples t-test and the analysis of variance (ANOVA) as seen in table 3 .

Table 3. Results of inferential statistics with interpretations and reference to corresponding appendix 


\begin{tabular}{|c|c|c|c|}
\hline Comparison & Test & Result & Conclusion \\
\hline $\begin{array}{l}\text { Knowledge } \\
\text { score and } \\
\text { Gender }\end{array}$ & t-test & $\begin{array}{c}p= \\
0.0987\end{array}$ & $\begin{array}{l}\text { There is no } \\
\text { statistically } \\
\text { significant difference } \\
\text { between knowledge } \\
\text { score and respondent } \\
\text { gender. }\end{array}$ \\
\hline $\begin{array}{l}\text { Knowledge } \\
\text { score and } \\
\text { Age }\end{array}$ & ANOVA & $\begin{array}{c}p= \\
0.758\end{array}$ & $\begin{array}{l}\text { There is no } \\
\text { statistically } \\
\text { significant difference } \\
\text { between knowledge } \\
\text { score and respondent } \\
\text { age. }\end{array}$ \\
\hline $\begin{array}{l}\text { Knowledge } \\
\text { score and } \\
\text { Education }\end{array}$ & ANOVA & $\begin{array}{c}p= \\
0.610\end{array}$ & $\begin{array}{l}\text { There is no } \\
\text { statistically } \\
\text { significant difference } \\
\text { between knowledge } \\
\text { score and respondent } \\
\text { education. }\end{array}$ \\
\hline $\begin{array}{l}\text { Knowledge } \\
\text { score and } \\
\text { Income }\end{array}$ & ANOVA & $\begin{array}{c}p= \\
0.248\end{array}$ & $\begin{array}{l}\text { There is no } \\
\text { statistically } \\
\text { significant difference } \\
\text { between knowledge } \\
\text { score and respondent } \\
\text { income. }\end{array}$ \\
\hline $\begin{array}{l}\text { Knowledge } \\
\text { score and } \\
\text { Housing } \\
\text { status }\end{array}$ & ANOVA & $\begin{array}{c}p= \\
0.762\end{array}$ & $\begin{array}{l}\text { There is no } \\
\text { statistically } \\
\text { significant difference } \\
\text { between knowledge } \\
\text { score and respondent } \\
\text { housing status. }\end{array}$ \\
\hline
\end{tabular}

\section{DISCUSSION}

This research project aimed to expand on the 2014 research project, conducted by Debbie Lee, entitled "A Study of Indoor Air Quality Investigations in B.C. Health Authorities". (1) According to this study, the IAQ complaint topic most encountered by EHOs working in $\mathrm{BC}$ was that of mould. Therefore, the objective of this research project was to evaluate the public perception of mould as an IAQ issue. As well, this study examined existing knowledge levels among Metro Vancouver residents and where they are likely to find information on the topic.

The results revealed that there was no difference between knowledge score and respondent gender, age, level of education, income or housing status. These results imply that any knowledge translation that may be designed to educate Metro Vancouver residents about the topic should not be focused on any one demographic group in particular but rather on the general public.

With an average 14.59 out of 20, respondent knowledge scores were, in general, fair. Most respondents $(n=108)$ achieved a knowledge score of 10 and higher, equivalent to $50 \%$ and over. While more than half achieved a knowledge score of 15 and higher, equivalent to $75 \%$ and over $(n=66)$. These knowledge scores suggest that the public is fairly knowledgeable when it comes to indoor mould. This finding was a little surprising. As mould complaints were one of the most received IAQ complaints reported by EHOs in $\mathrm{BC}$, public knowledge of the topic was anticipated to be low. (1) That being said, based on specific respondent answers, there may be a few topic areas in which gaps in knowledge exist. For example, some respondents believed that all species of mould can potentially cause harm to humans. The link between each species of mould and adverse health effects has not been investigated, therefore there is no way of knowing conclusively that all species of mould can potentially harm humans. (21) Evidence suggests that there are some species which have conclusively been associated with adverse health effects, such as Alternaria, Stachybotrys, and Penicillium, to name a few. (11) 
Additionally, few respondents selected a face mask as their PPE of choice when cleaning mould while many preferentially selected rubber gloves. This may mean that the sample population did not have a good understanding of mould exposure pathways. Appropriate PPE would be selected when exposure pathways are well understood. While exposure to mould can include dermal contact, inhalation or ingestion, inhalation is the most harmful pathway for exposure and therefore the most appropriate PPE is a face mask at the very least. $(2,4,8,10,16,19)$

Not surprisingly, when given a choice of resources they might utilize to learn more about mould and mould remediation recommendations, the vast majority of respondents answered that they would use "an internet search". This indicated that most of the sample population did not know specifically where to access reliable information on this topic. It would appear that the reliable sources listed in the literature review, including the NCCEH, the $\mathrm{CMHC}$, the Government of Canada including Health Canada, HealthLinkBC, or WorkSafeBC are therefore not known to the public as sources for information on this topic. $(8,10,11,16,19,20,28)$

Due to the small sample size, the knowledge score results yielded may not be valid. However, in general, some of the results relating to specific questions, may be able to aid Public and Environmental Health practitioners when addressing queries and complaints from the public. For example, when recommending external sources of information.

\section{Limitations}

Limitations of this study included lack of participation in the survey. The small sample size of 119 respondents reduced the external validity of the results. (33) This could be mitigated, if time were not a constraint, by keeping the survey open longer. Or alternatively, by expanding the inclusion and exclusion criteria and opening the survey to allow a broader base population. (34)

Additionally, the survey was dependent on respondents answering honestly and without any aid, however due to the selfadministered nature of the method selected, reliability and validity cannot be guaranteed. If time was not a limitation, an interview via telephone or in person would increase the reliability and validity in this regard.

Another limitation was that of access. The method selected for the survey relied on people having access to a computer as well as the Internet, which may have minimally limited responses. This could be mitigated by utilizing an additional distribution method such as either of the interview styles previously mentioned. (35)

\section{Knowledge Translation}

Overall knowledge of mould as an IAQ issue was found to be fair, therefore education on the topic may not be necessary. However, as Lee's research showed, EHO's in $B C$ do receive IAQ complaints regarding mould. In addition, the fact that respondents answered that they would use 
"an internet search" to retrieve more information, may mean that reliable sources are not easily accessible to, or known by, the public. By making the information from valid and reliable sources easier to find on the Internet this may ensure that the public is not accessing, and therefore not acting on, misinformation. Resources such as the NCCEH or CMHC could additionally collaborate in a public education campaign to generate public interest in reliable information. Educational material such as infographics could be designed to address the specific gaps in knowledge identified. For example, an infographic with schematics of the exposure pathways of mould and appropriate PPE to protect oneself from exposure during mould clean up.

As referenced in the literature review, only two of the five Health Authorities in BC currently mention mould on their websites. Fraser Health links to the HealthLinkBC web page listed in the reliable resources list and Northern Health has a tab entitled "Mold: Mold in Your Home" on their Health Built Environment webpage. $(24,25)$ By specifically addressing the topic on their web pages and linking to reliable resources, the Vancouver Coastal, Vancouver Island and Interior Health Authorities could save resources including EHO time and energy. By having web pages devoted to the topic, EHOs may not receive as many inquiries or complaints by telephone from the public. If still received, EHOs would no longer have to refer these to external sources but would rather refer them to the HA webpage which can address their questions.

Additionally, EHOs could participate in IAQ public engagement events and present at public meetings in collaboration with agencies mentioned as the credible sources for information on mould, such as the NCCEH, to promote awareness amongst the public.

\section{Future Research}

Based on the results of this study, further research may be pursued in the following areas:

- An investigation of the public perception of mould as an IAQ issue for all British Columbia residents or, alternatively, for all residents of Canada.

- An evaluation of the number of IAQ and mould inquiries and complaints received by BC Health Authorities that do address this topic on their website compared to those that do not.

- An investigation of the public knowledge regarding appropriate personal protective equipment (PPE) measures when conducting their own work at home e.g. minor or major mould remediation.

\section{CONCLUSION}

The purpose of this study was to evaluate the public perception of Metro Vancouver residents regarding mould, one of the top IAQ complaints received by EHOs in BC. The study determined that there was no difference between knowledge score of participants relating to mould and their corresponding gender, age, level of education, income or housing status. 
Although knowledge scores were fair, a few gaps in knowledge were identified, including exposure pathways of mould. The insights from this study may be useful for Public and Environmental Health professionals when addressing queries from the public regarding this topic.

\section{ACKNOWLEDGEMENTS}

The authors would like to acknowledge the British Columbia Institute of Technology Environmental Health department, specifically Dr. Helen Heacock and Frederick Shaw, as well as all those who participated in the study.

\section{COMPETITION INTERESTS}

The authors declare that they have no competing interests.

\section{REFERENCES}

1. Spellman FR. Indoor Air Quality. In: The Science of Air, Concepts and Applications [Internet]. Second Ed. CRC Press; 2008. p. 245-79. Available from: http://sel.me.wisc.edu/publicationstheses.shtml

2. Vancouver Coastal Health Authority. Indoor Air Quality [Internet]. 2017 [cited 2017 Oct 18]. Available from: http://www.vch.ca/publichealth/environmental-healthinspections/healthy-builtenvironment/air-quality/indoor-airquality

3. Lee D, Heacock H, Sidhu B. A Study of Indoor Air Quality Investigations in B.C. Health Authorities. 2013.

Available from: https://circuit.bcit.ca/repository/islando ra/object/repository\%3A26/datastream/ PDF/view
4. Singh J. Occupational exposure to moulds in buildings. Indoor Built Environ. 2001;10(3-4):172-8.

5. Hostland C, Sadiq R, Lovegrove G, Roberts D. HEALTH(2): A Holistic Environmental Assessment Lay Tool for Home Health. Can J Civ Eng. 2015;42(4):241-9.

6. Osterberg PM. Indoor Mould, Dust Mite and Endotoxin Exposure in Aboriginal Housing in British Columbia: An Assessment of the Heiltsuk First Nation Community. The University of British Columbia; 2009.

7. Major JL, Boese GW. Cross Section of Legislative Approaches to Reducing Indoor Dampness and Mold. J Public Heal Manag Pract [Internet]. 2017;23(4):388-95. Available from: http://insights.ovid.com/crossref?an=00 124784-201707000-00010

8. WorkSafeBC. Guidelines Part 4 Indoor air quality. 2007;79(1). Available from:

https://www.worksafebc.com/en/lawpolicy/occupational-healthsafety/searchable-ohs-regulation/ohsguidelines/guidelines-part04?origin=s\&returnurl=https\%3A\%2F\%2 Fwww.worksafebc.com\%2Fen\%2Fsearch \%23q\%3Dmold\%26sort\%3Drelevancy\%2 6f\%3Alanguage-facet\%3D\%5BEngli

9. World Health Organisation. Dampness and Mould. WHO Guidelines for Indoor Air Quality. J Biomed Semantics [Internet]. 2011;2(Suppl 2):I1. Available from: http://jbiomedsem.biomedcentral.com/ articles/10.1186/2041-1480-2-S2-I1

10. Government of Canada. Mould and Your Health [Internet]. 2012. 
Available from:

https://www.canada.ca/content/dam/hc -sc/migration/hc-sc/fniah-

spnia/alt_formats/pdf/promotion/public -publique/home-maison/mouldmoisissure-eng.pdf

11. Shum M, Clements L. National Collaborating Centre for Environmental Health (NCCEH) Microbial Investigation Toolkit. 2014. Available from: http://www.ncceh.ca/sites/default/files/ Mould_Toolkit_Typical_Fungi_Nov_2014 .pdf

12. Krause M, Geer W, Swenson L, Fallah P, Robbins C. Controlled study of mold growth and cleaning procedure on treated and untreated wet gypsum wallboard in an indoor environment. J Occup Environ Hyg. 2006;3(8):435-41.

13. Cox-Ganser J, Park J, Kanwal R. Epidemiology and Health Effects in Moisture-Damaged Damp Buildings. In: Goldstein WE, editor. Sick Building Syndrome and Related Illness, Prevention and Remediation of Mold Contamination. CRC Press; 2010. p. 1122.

14. Krieger J, Higgins DL. Housing and health: Time again for public health action. Am J Public Health.

2002;92(5):758-68.

15. Optis M, Shaw K, Stephenson P, Wild P. Mold Growth in On-Reserve Homes in Canada: The Need for Research, Education, Policy, and Funding. J Environ Health [Internet]. 2012;74(6):14-21. Available from: http://media.proquest.com/media/pq/cl assic/doc/2562686471/fmt/pi/rep/NON E?hl=\&cit\%3Aauth=Optis\%2C+Michael\% 2C+MASc\%3BShaw\%2C+Karena\%2C+Ph
D\%3BStephenson\%2C+Peter\%2C+PhD\% 3BWild\%2C+Peter\%2C+PhD\&cit\%3Atitle $=$ Mold + Growth + in + On-

Reserve+Homes+in+Canada\%3A+The+N eed

16. Canada Mortgage and Housing Corporation. Moisture and Air. A Guide for Understanding and Fixing Interior Moisture Problems in Housing [Internet]. 2015; Available from: https://www.cmhcschl.gc.ca/odpub/pdf/61033.pdf 17. Small BM. Creating mold-free buildings: a key to avoiding health effects of indoor molds. Arch Environ Health. 2003;58(8):523-7.

18. Polyzois D, Polyzoi E, Wells JA, Koulis T. Poor Indoor Air Quality, Mold Exposure, and Upper Respiratory Tract Infections--Are We Placing Our Children at Risk? J Environ Health [Internet]. 2016;78(7):20-7. Available from: http://www.ncbi.nlm.nih.gov/pubmed/2 7197351

19. Health Canada. Residential Indoor Air Quality Guidelines: Mould [Internet]. 2007; Available from: https://www.canada.ca/en/healthcanada/services/publications/healthyliving/residential-indoor-air-qualityguideline-moulds.html

20. Shum M, Palatay C. National Collaborating Centre for Environmental Health (NCCEH). Mould Remediation Recommendations [Internet]. 2014; Available from: http://www.ncceh.ca/sites/default/files/ Mould_Remediation_Evidence_Review_ March_2014.pdf

21. Centers for Disease Control and Prevention. Molds in the Environment 
[Internet]. 2017. Available from:

https://www.cdc.gov/mold/faqs.htm\#in door

22. Haverinen-Shaughnessy $U$, Hyvärinen A, Putus T, Nevalainen A. Monitoring success of remediation: Seven case studies of moisture and mold damaged buildings. Sci Total Environ. 2008;399(1-3):19-27.

23. Government of British Columbia. Health Authorities [Internet]. 2017. Available from: https://www2.gov.bc.ca/gov/content/he alth/about-bc-s-health-caresystem/partners/health-authorities

24. Fraser Health Authority. Indoor Air Quality [Internet]. Available from: http://www.fraserhealth.ca/healthinfo/health-topics/air-quality/indoor-airquality/indoor-air-quality

25. Northern Health Authority. Healthy Built Environments [Internet]. 2017. Available from: https://www.northernhealth.ca/YourHe alth/EnvironmentalHealth/HealthyBuiltE nvironments.aspx

26. Vancouver Island Health Authority. Air Quality [Internet]. 2017. Available from:

https://www.interiorhealth.ca/YourEnvir onment/AirQuality/Pages/default.aspx

27. Interior Health Authority. Air Quality [Internet]. 2017. Available from: https://www.interiorhealth.ca/YourEnvir onment/AirQuality/Pages/default.aspx

28. HealthLinkBC. Indoor Air Quality: Mould and Other Biological Contaminants [Internet]. 2014. Available from:

https://www.healthlinkbc.ca/healthlinkb c-files/air-quality-mould
29. Google Inc. Google Forms [Internet]. 2017 [cited 2017, Nov 01]. Available from: https://www.google.ca/forms/about/

30. Google Inc. Google Sheets [Internet]. 2017 [cited 2017, Nov 10]. Available from: https://www.google.com/sheets/about/

31. NCSS, LLC. NCSS 11 Statistical Software; 2016.

32. Metro Vancouver. 2006 Census Bulletin \# 4: Dwellings by Type and Tenure [Internet]. 2007 [cited 2017, Nov 01]. Available from: http://www.metrovancouver.org/service s/regionalplanning/PlanningPublications/2006cens us_dwell_Dec2007.pdf

33. British Columbia Institute of Technology. Research Ethics for Human Participants Policy [Internet]. 2011 [cited 2017, Nov 02] Available from: https://www.bcit.ca/files/pdf/policies/6 500.pdf

34. Wang $\mathrm{R}$, Yang $\mathrm{Y}$, Chen $\mathrm{R}$, Kan $\mathrm{H}, \mathrm{Wu}$ J, Wang $\mathrm{K}$, et al. Knowledge, Attitudes, and Practices (KAP) of the Relationship between Air Pollution and Children's Respiratory Health in Shanghai, China. Int J Environ Res Public Health. 2015;12(2):1834-48.

35. Reliability and Validity [Internet]. [cited 2018 Mar 14]. Available from: http://psc.dss.ucdavis.edu/sommerb/so mmerdemo/intro/validity.htm 